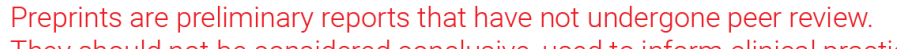 They should not be considered conclusive, used to inform clinical practice, or referenced by the media as validated information. \\ a-Tomatine Inhibits Proliferation, Metastasis, Drug Resistance and Immune Infiltration Through the PI3K-AKT-MAPK Axis in Gastric Cancer
}

\section{Di Zhang}

Guangxi Medical University Cancer Hospital Hao Yuan

Guangxi Medical University Cancer Hospital

\section{Si-Si Mo}

Guangxi Medical University Cancer Hospital

\section{Xian-Wei Mo}

Guangxi Medical University Cancer Hospital

Wei-Zhong Tang

Guangxi Medical University Cancer Hospital

Lin-Hai Yan ( $\nabla$ lhyan@gxmu.edu.cn )

Guangxi Medical University Cancer Hospital

\section{Research article}

Keywords: GC, a-tomatine, AKT, MAPK, proliferation, metastasis, drug resistance, immune infiltration

Posted Date: August 26th, 2020

DOl: https://doi.org/10.21203/rs.3.rs-53224/v1

License: (1) This work is licensed under a Creative Commons Attribution 4.0 International License. Read Full License 


\section{Abstract}

Background: a-Tomatine, a naturally existing steroidal glycoalkaloid in immature green tomatoes, had anticarcinogenic performances in various types of cancer cells. Within this study, we aimed to investigate the efficacy and potential molecular mechanism of a-tomatine in gastric cancer (GC) and the association with immune infiltration and prognosis.

Methods: We used human GC cells MGC803, BGC823, SGC7901 and SGC7901/DDP to evaluate the cell functions of a-tomatine, and the molecular mechanisms of a-tomatine were investigated by qRT-PCR and western blotting analysis. Timer database was used to analyzed the correlation of targets repressed by atomatine, immune infiltration and prognosis.

Results: Results showed that a-tomatine strongly inhibited PI3K-AKT and MAPK signaling pathways, thereby repressing the proliferation and metastasis of GC cells with different differentiations and cisplatin resistance. The inhibitory effect of a-tomatine on TWIST, Slug and PARP in SGC7901/DDP cells also suggested a-tomatine provided a feasible approach for confronting metastasis of clinical cisplatin resistant cases. Immunologically, a-tomatine could partially modulate the process and consequences of immune infiltration based on the correlation between 65 genes corresponding to interacting proteins and immune cell infiltration. a-Tomatine could improve prognosis of GC patients by inhibiting AKT3, VIM, FN1 and SNAI2, and at least partially counteract immune dysfunction triggered by macrophage infiltration.

Conclusion: Strategies for treating GC should not be restricted to single, repetitive drug use, they should be predisposed to emerging, multi-target drugs. GC was highly susceptible to a-tomatine suggesting that a-tomatine could be used as an emerging and promising approach to confront GC.

\section{Background}

While the high morbidity and mortality of GC has decreased due to the widespread use of targeted drugs in the clinic, it is still the third most lethal cancer in the world due to its high rate of recurrence, metastasis and multidrug resistance [1]. Existing circulating biomarkers show lower sensitivity and specificity for early diagnosis and prognosis of GC. Unfortunately, the molecular mechanism of MDR is complex, which also greatly limits the effect of targeted drugs against GC targets. This current situation urgently requires the occurrence of emerging drugs that could be used in the therapy of GC to prolong the survival and improve the quality of life of GC patients.

Tumor proliferation and metastasis occur through a distinct conversion of genetical characteristic and various cellular physiological changes, including malignant proliferation of cancer cells, elevated interaction between cancer cells and the extracellular matrix (ECM), damaged ECM elements and angiogenesis [2]. Previous studies have found that the PI3K-AKT signal transduction pathway is crucial to induce the proliferation and metastasis of human non-small cell lung cancer (NSCLC) and is strongly associated with the oncogenesis of several types of cancer [3]. AKT kinase, a significant element of the proliferation and apoptosis signaling pathway, is activated through the PI3K signaling pathway [4]. 
Members of the mitogen-activated protein kinase (MAPK) superfamily are related to elevated morphogenesis, amplification, apoptosis, movement and invasion capacity of cells [5-7]. The MAPK signaling cascades are made up of three main MAP kinases including extracellular signal-regulated kinases 1 and 2 (ERK1/2), c-Jun N-terminal kinase/stress-activated protein kinase (JNK/SAPK), and p38 MAPK [8-11]. Multiple phospho-MAP kinase members, modulated by different extramural signals, activate downstream targets so as to take effects in cellular signal transduction. Furthermore, the molecular mechanism of MDR is complex, which is thought to be involved in drug transport, drug pumping, intracellular drug metabolism, DNA damage, DNA repair and apoptosis [12]. Simultaneously, tumorigenesis is not effectively suppressed due to immune dysfunction. "Non-self" tumor cells are specifically eliminated by the immune system characteristic for a monitor through cellular immune mechanism to maintain the stability of internal environment. However, tumor cells rapidly divide and proliferate in the body thereby accelerating tumor progression when they escape the immune system by various factors. Chemokines and antigens expressed by tumor cells induce mass infiltration of immune cells, whereas tumor cells induce immune escape by down-regulating or blocking tumor antigens and their own low immunogenic [13]. Infiltration of immune cells may stimulate activation of tumor-related pathways via secrete cytokines, further exacerbating tumor progression.

a-Tomatine is a sort of glycoalkaloids, naturally extracted in unripe green tomatoes ( $500 \mathrm{mg} / \mathrm{kg}$ of fresh fruit) [14]. As the tomato matures, the ingredient is partially degraded until the ripening level of the red tomato is about $5 \mathrm{mg} / \mathrm{kg}$ of fresh fruit $[11,15]$. a-Tomatine is composed of an aglycone moiety (tomophylline) and a tetrasaccharide moiety ( $\beta$-glycolipid), which contains two D-glucose molecules, one D-galactose and one D-xylose (Fig. 1A). Previous studies showed that a-tomatine resulted in the negative regulation of proliferation and apoptosis, thereby repressing the amplification of human colorectum and liver-derived cancer cells $[16,17]$. Moreover, a-tomatine modulated T cell-mediated inhibition of mouse lymphoid tumor EG7-Ova and took effects as an anti-inflammatory drug by confronting nuclear factor kappa B (NF-KB) and JNK signaling in macrophages of mouse [18-20]. To evaluate the molecular mechanism of a-tomatine against GC, we used human GC cells MGC803, BGC823, SGC7901 and SGC7901/DDP to elucidate the specific role of a-tomatine in cell function and molecular mechanism, so as to reveal its inhibitory effect on proliferation, metastasis, drug resistance and immune infiltration of $\mathrm{GC}$, and to provide the possibility that a-tomatine could be a potential drug for the treatment of GC.

\section{Methods}

\section{Test Compound}

a-Tomatine purchased from Chengdu Must Bio-Technology Co., Ltd (Chengdu, China), dissolved in dimethyl sulfoxide (DMSO) purchased from Beijing Solarbio Science and Technology Co., Ltd, and stored at $-20^{\circ} \mathrm{C}$. The purity was [ $\geq 98 \%$, as assessed by HPLC-ELSD].

\section{Cell Culture}


Human gastric cells MGC803, BGC823 and SGC7901 SGC7901/DDP were purchased from Cell Bank of BeNa culture collection (Beijing, China). SGC7901/DDP were purchased from MeiXuan Biological science and technology Ltd (Shanghai, China). Above-mentioned cell lines were cultured in DMEM/RPMI-1640 medium (Gibco, USA) with 10\% FBS (Lonsera, South America) and $2 \%$ Penicillin-Streptomycin (Solarbio, China). All cells were cultured at $37^{\circ} \mathrm{C}$ in a humidified atmosphere of $5 \% \mathrm{CO} 2-95 \%$ air. Phosphate buffer solution (Solarbio, China) and trypsin-EDTA (Solarbio, China) were used for cell washing and digestion respectively.

\section{Cell Viability Assay}

To measure the effect of a-tomatine on cell multiplication capacity, Human gastric cells MGC803, BGC823, SGC7901 and SGC7901/DDP were seeded in 96-well plates (1×104 cells/well). Cells were treated with or without a-tomatine under various concentrations. Cell viability was measured by the CCK-8 assay (Becton-Dickinson, USA) at the end of 24 hours, $10 \mu \mathrm{L}$ of the 2- (2-methoxy-4-nitrophenyl) -3- (4nitrophenyl) -5- (2,4-disulfobenzene) -2H-tetrazole monosodium salt was co-incubated with each well for $2 \mathrm{~h}$. Absorbance was tested at $450 \mathrm{~nm}$ spectrophotometrically. The percentages of cells viability treated with a-tomatine in different concentrations were estimated by comparing with the untreated control cells. Each concentration was repeated three times.

\section{Apoptosis analysis by flow cytometry}

Cell apoptosis were performed by Annexin V-APC/PI staining method (Becton-Dickinson, USA) following the manufacturer's protocol. Cells were suspended in 6-well plates at $1 \times 105$ cells/well and incubated with Annexin V-APC and propidium iodide $(\mathrm{PI})$ at $4^{\circ} \mathrm{C}$ for $30 \mathrm{~min}$. The cell suspensions were then analyzed by Flow cytometry, and repeated all experiment three times.

\section{Wound-healing assay}

For cell motility assay, gastric cells $(2 \times 105$ cells $/ \mathrm{ml})$ were seeded in 6-well plates and grown to a density of about $80 \%$ to $90 \%$. Before changing the medium, the cells in the well plate were scraped with a yellow sterile micropipette tip to form a constant-width, neat-edge wound area. The scraped cells were then washed three times with PBS, and gastric cells were cultured to various concentrations of a-tomatine ( 0 , $1,1.5$, and $2 \mu \mathrm{M})$.

The movements of cells were observed and photographed at 0,24 and $48 \mathrm{~h}$ in serum-free medium. We compared the wound area of a-tomatine-treated pores with those of the control group to quantify migrated cells. 3 positions were randomly selected for each concentration, and the remaining area of the wound was marked with ImageJ at different times.

\section{Western Blotting Analysis}

Gastric cells were collected and lysed by RIPA lysis buffer (Epizyme, Shanghai, China). After cells were fully lysed, added the protein loading buffer, boiled the protein at $95^{\circ} \mathrm{C}$ for 10 minutes to denature it, and 
stored it at $-20^{\circ} \mathrm{C}$. The Western blotting was performed as follows. The electrophoresis of denatured samples was conducted on 10\% PAGE gel fast preparation kit (Epizyme, Shanghai, China). The proteins were then transferred onto polyvinylidene fluoride (PVDF) membranes for $110 \mathrm{v}, 70$ minutes. Non-specific binding of the membranes was blocked with Tris-buffered saline (TBS) containing $5 \%$ non-fat dry milk and $0.1 \%$ Tween-20 (TBST) for more than $1 \mathrm{~h}$. Membranes were washed with TBST three times for 10 min and incubated with an appropriate dilution of specific primary antibodies (anti-AKT: 1:1000, antiphospho-AKT: 1:1000, anti-MEK1/2: 1:1000, anti-phospho-MEK1/2: 1:2000, anti-ERK1/2: 1:1000, antiphospho- ERK1/2: 1:2000, purchased from Cell Signaling Technology, USA) in TBST overnight at $4{ }^{\circ} \mathrm{C}$. Subsequently, membranes were washed with TBST three times for $10 \mathrm{~min}$ and incubated with appropriate secondary antibody (horseradish peroxidase-conjugated goat anti-mouse or anti-rabbit IgG, purchased from ZSGB-BIO, Beijing, China) for $1 \mathrm{~h}$. After washing the membrane three times for $10 \mathrm{~min}$ in TBST,

Signals were recorded by using the ECL Western Blotting Kit (Pierce, USA), and quantified the result by ImageQuant LAS 4000 (GE Healthcare, USA). The membranes were co-incubated with first anti-GAPDH (1:1000, purchased from ComWin Biotech Beijing China) and anti-goat second antibody (ZSGB-BIO, Beijing, China) for normalization.

\section{Quantitative reverse-transcriptase real-time polymerase chain reaction (qRT-PCR)}

Total RNA was extracted from each group cells using TRIzol Reagent Kit (Invitrogen, USA), and then performed by quantitative reverse-transcriptase real-time polymerase chain reaction (qRT-PCR). Total RNA $(2 \mu \mathrm{g})$ was transcribed to $20 \mu \mathrm{l}$ cDNA with $10 \mu \mathrm{l} 2 \times$ TransScript Reaction Mix, $1 \mu \mathrm{l}$ TransScript RT/RI Enzyme Mix, $1 \mu$ l Oligo (DT), $1 \mu$ l gDNA Remover and RNase-free Water. The appropriate primers (sense of GAPDH, 5'- GATTCCACCCATGGCAAATTCC -3', antisense of GAPDH, 5'- GCATCGCCCCAC TTGATTTT -3', sense of AKT, 5' - TACGAGATGATGTGCGGTCG -3', antisense of AKT, 5'- CAGCCCTGAAAGCAAGGACT -3', sense of ERK1, 5'- ACTCCAA AGCCCTTGACCTG -3', antisense of ERK1, 5'- GGGACTGGCCCACCTCAT -3', sense of ERK2, 5'- GGCTGTTCCCAAATGCTGAC -3', antisense of ERK2, 5'- CTCGTCACTCGGGTCGTAAT -3', sense of TWIST, 5'- GGAAGATC ATC CCCACGCTG -3', antisen se of TWIST, 5'- GCTCTGGAGGACCTGGTAGA -3', sense of Slug, 5'- CGGGGGAGAAGCCTTTTTCT -3', antisense of Slug, 5'- CACAGCAGCCAGATTCCTCA -3', sense of PARP, 5'- CCTCCTCCTACCTCT GGTGC -3', antisense of PARP, 5'- CTGGACAGATGCCTTTCGCT -3', sense of Vimentin, 5'- TGGCACGTCTTGACCTTGAA -3', antisense of Vimentin, 5'-

GGCTTGGAAACATCCACATCG -3', sense of Caspase-3, 5'- CCTGGTTCATCCA GTCGCTT -3', antisense of Caspase-3, 5'- TCTGTTGCCACCTTTCGGTT -3', sense of N-cadherin, 5'- GGGAATCCGACGAATGGATGA -3', antisense of N-cadherin, 5'- GAGCCACTGCCTTCATAGTCA -3') were used for quantitative reversetranscriptase real-time polymerase chain reaction (qRT-PCR). qRT-PCR was performed with Taq polymerase (TransGen Biotech, Beijing, China) according to the following conditions: $95^{\circ} \mathrm{C}$ for $10 \mathrm{~min}, 40$

cycles of $95^{\circ} \mathrm{C}$ for 2 seconds; $60^{\circ} \mathrm{C}$ for 20 seconds and $70^{\circ} \mathrm{C}$ for 10 seconds. All mRNA expressions were calculated by using the $2-\Delta \Delta \mathrm{Ct}$ method, and repeated all experiment three times. The values were presented as mean \pm SD. 


\section{PPI networks construction}

The significant associations of protein-protein interactions (PPIs) are provided in STRING database (http://string-db.org/) [21]. The visual explorations of interaction networks were conducted by Cytoscape [22]. In our works, we used multiple protein model in STRING database to build the PPI networks of PI3KAKT and Ras-Raf-MAPKs signal pathways across 3 functional states in GC. Followed of which, we used Cytoscape to visualize the PPI networks [23]. The medium confidence was set at 0.400 .

\section{TIMER database analysis}

The analysis of the immune infiltrates across different types of tumor are conducted by The TIMER database (https://cistrome.shinyapps.io/timer/) [24]. We used Diff Exp module to explore differential expressions of 8 genes (PIK3R1, AKT1, AKT2, AKT3, MEK1, MEK2, ERK1 and ERK2) between tumor and its adjacent normal tissue. Gene module to explore the relationship between 8 genes mentioned above and their associated genes and immune infiltration levels of 6 immune cells (B cell, CD4+T cell, CD8+T cell, macrophage, neutrophil, dendritic cell). Survival module to explore the clinical relevance of immune cells (Cox regression analysis and Kaplan-Meier analysis). In addition, we analyzed the association between the expression levels of specific genes and the infiltration levels of tumor purity and 6 immune cells.

\section{Statistical Analysis}

SPSS version 13.0 (SPSS, Chicago, USA) was used for all statistical analyses. Data were expressed as the mean \pm standard error of mean (S.E.M), and statistical significance was carried out using t-tests and one-way ANOVA. Significant differences were established at $\mathrm{P}<0.05$. All analyses were conducted with GraphPad Prism 5 software (GraphPad Software, Inc., San Diego, CA).

\section{Results}

\section{The proliferation ability of GC cells was inhibited by a-tomatine}

In contrast to normal cells, tumor cells manifest a variety of pathological states, especially a significant increase in amplification capacity. Cancer is an inevitable consequence when the gene mutation of cells in vivo cannot be effectively inhibited, leading to uncontrolled growth [25]. To investigate the effect of atomatine on the proliferation of GC cells, the proliferation activity of MGC803, BGC823, SGC7901 and SGC7901/DDP were analyzed by CCK8 kit. The results showed that the proliferation of the GC cells at the different levels of differentiation was significantly inhibited by a-tomatine, compared with the control group. The proliferation of these $4 \mathrm{GC}$ cells experienced a significant decrease by the intervention concentration of a-tomatine at $1.5 \mu \mathrm{M}$ (Fig. 1B), suggesting that a-tomatine exerted a strong inhibitory effect on GC cells at this concentration. Moreover, the IC50 values of $4 \mathrm{GC}$ cells that we calculated were $1.412 \pm 0.108,1.055 \pm 0.047,1.147 \pm 0.142,1.250 \pm 0.156$, respectively (Fig. 1C). Intriguingly, the proliferation of 7901/DDP cell was also inhibited by a-tomatine. These results clearly demonstrated that 
a-tomatine could effectively reduce the amplification ability of GC cells with varying degrees of differentiation or resistance to cisplatin.

\section{The apoptosis of GC cells was facilitated by a-tomatine}

Apoptosis is a gene-oriented programmed death, which is to effectively eliminate dysfunctional cells [26]. Inhibition of tumor cells from auto-apoptosis often makes them predisposed to neoplastic evolution occurrence so as to induce tumorigenesis and drug resistance. As for cell proliferation, a-tomatine also could affect GC cell apoptosis. Apoptosis of GC cells were measured by flow cytometry to analyze the effect of a-tomatine on apoptosis. We tested the apoptosis of MGC803, BGC823, SGC7901 and SGC7901/DDP treated with $1 \mu \mathrm{M}$ of a-tomatine 24 hours. The results showed that the percentage of early and late withering of the $4 \mathrm{GC}$ cells increased significantly after treatment with a-tomatine compared with corresponding control group, suggesting that a-tomatine could significantly increase the apoptosis rate of GC cells. The apoptotic rates of MGC803 and SGC7901 cells treated without or with a-tomatine were $6.07 \% \pm 1.63 \%$ vs. $22.93 \% \pm 2.75 \%$ and $7.53 \% \pm 1.94 \%$ vs. $29.70 \% \pm 3.32 \%$ (Fig. 2 A and $2 B$ ). Similarly, the apoptosis of 7901/DDP cell was also increased by a-tomatine. The above results demonstrated that $\mathrm{a}-$ tomatine could mediate apoptosis of different degrees of differentiation and cisplatin-resistant GC cells.

\section{a-Tomatine inhibited the migration activity of GC cells}

Migration, with respect to metastasis, is another important feature of tumor cells [26]. Metastasis is often associated with the progression of gastric cancer. Whether metastasis has become one of the main factors affecting prognosis and survival [27]. We tested the healing area of the scratches of $4 \mathrm{GC}$ cells treated with different concentrations of a-tomatine $(0,0.5,1$ and $2 \mu \mathrm{M})$ in a serum-free medium and photographed and recorded at $0 \mathrm{~h}, 24 \mathrm{~h}$ and $48 \mathrm{~h}$. The result showed that a-tomatine could effectively increase the healing area of the wound, and the area increases with up-regulation of the concentration of a-tomatine, compared with those of the non-a-tomatine-treated group. (Fig. 3A-D). The effect of atomatine intervention concentration of $2 \mu \mathrm{M}$ on the migration ability of the $4 \mathrm{GC}$ cells was more than $40 \%$. On the premise that the own proliferation of cells was ruled out as much as possible, these results exhibited that a-tomatine could effectively inhibit the athletic ability of cells thereby inhibiting metastasis of different degrees of differentiation and cisplatin-resistant GC cells.

\section{Landscape of PIK3R1, AKT1, AKT2, AKT3, MEK1, MEK2, ERK1 and ERK2 expression levels in distinct cancers}

Available evidences manifested that over activation of PI3K-AKT and MAPKs pathways is the crucial mediator of tumor proliferation and metastasis. To investigate features of above pathways in distinct cancers, cognition of the difference of expression levels of core genes is necessary. We analyzed the expression levels of 8 genes including PIK3R1, AKT1, AKT2, AKT3, MEK1 (MAP2K1), MEK2 ((MAP2K2), ERK1 (MAPK3) and ERK2 (MAPK1) in distinct human cancers. Data from the TIMER database suggested that the expression levels of AKT1, MEK1 and ERK2 were significantly up-regulated in GC comparing with normal tissue (Fig. 4), as well as in BRCA (bladder urothelial carcinoma), CHOL (cholangiocarcinoma), 
HNSC (head and neck cancer) comparing with normal tissue. However, the difference of the other genes was not statistically significant in GC (data was not shown).

\section{a-Tomatine suppresses the PI3K-AKT signaling pathway and MAPK signal cascade pathway in GC cells}

The above experiments proved that a-tomatine could inhibit the proliferation and metastasis of GC cells, and the inhibition was positively correlated with higher concentrations. Furthermore, cancer progression is often accompanied by abnormal expression of oncogenes and corresponding proteins. To further clarify the underlying mechanism of a-tomatine, we investigated the effect of a-tomatine on the constitutive activation status of AKT and a major mammalian MAPKs (ERK1/2). Western blot was used to detect the AKT, phospho-AKT, MEK1/2, phospho-MEK1/2, ERK1/2 and phospho-ERK1/2 protein levels in BGC823, SGC7901 and SGC7901/DDP cells treated with a-tomatine $(0,0.5,1$ and $2 \mu \mathrm{M})$ for $24 \mathrm{~h}$. The result demonstrated that intervention of a-tomatine suppressed the AKT, phospho-AKT, MEK1/2, phosphoMEK1/2, ERK1/2 and phospho-ERK1/2 expression levels in a dose-dependent manner (Fig. 5). We further investigated the expression of AKT, ERK1 and ERK2 at mRNA levels. Similarly, the results of RT-PCR indicated that a-tomatine repressed the mRNA expression of AKT, ERK1 and ERK2 in a dose-dependent manner (Fig. 6A and 6B). These results indicated that a-tomatine could down-regulate the PI3K-AKT signaling pathway and MAPK signal cascade pathway at transcription and protein levels, partially explaining the mechanism by which a-tomatine inhibited the proliferation and metastasis of gastric cancer.

\section{a-Tomatine inhibits TWIST, Slug and PARP mRNA expression in 7901/DDP cells, which are crucial during epithelial-mesenchymal transition}

Aberrant epithelial-mesenchymal transition (EMT) activation is considered a key step in the promotion of cancer metastasis, as it increases cancer cell motility and invasiveness [28]. EMT is unmasked a crucial approach in the progression and metastasis of tumor [28]. RT-PCR assay was used to investigate the repressed effect of a-tomatine on the transcription levels of those regulators associated with EMT, including TWIST, Slug, PARP, Vimentin, Caspase-3 and N-cadherin [29-34]. The results of RT-PCR showed that a-tomatine down-regulated the mRNA expression of TWIST, Slug and PARP in SGC7901/DDP, whereas no significant difference was uncovered in the expression of Vimentin, Caspase-3 and Ncadherin, which was not statistically significant (data was not shown). Under the effect of the highest concentration $(2 \mu \mathrm{M})$ of tomatine, the expression levels of these three genes decreased by $73 \%, 62 \%$, and $37 \%$, respectively (Fig. 7A and 7B). These results illustrated that a-tomatine down-regulated the mRNA expressions of TWIST, Slug and PARP at the transcription level and acted as a crucial role during EMT so as to remedy cisplatin-resistant gastric cancer.

\section{Interaction between PI3K-AKT and MAPKs pathways and proteins related to tumorigenesis, metastasis, metabolism}

To further clarify and predict the mechanisms associated with PI3K-AKT and MAPK pathways, we selected proteins with different subtypes on these pathways and proteins evidently related to three 
molecular biological functions involving tumorigenesis, metastasis and metabolism, to construct proteinprotein interaction (PPI) networks. Results showed that significantly interrelations were cognized to exist between the majority of the above 65 proteins (Supplementary table 1), typically illustrated by AKT1FOXO3, AKT3-GSK3B and MAPK3-JUN (Fig. 8A). Considering the interaction between pathway-associated proteins and function-associated proteins, it is reasonable to presume that a-tomatine inhibits the activation of PI3K-AKT and MAPK pathways and proteins interacting with the pathways. The effects of atomatine are not only restricted to anti-proliferation and anti-metastasis by repressing PI3K-AKT and MAPK pathways, but also modulates proteins involved in tumorigenesis, metastasis, metabolism. Certainly, nor can we exclude that this anti-proliferative and anti-metastatic effect is essentially the effect of these proteins when they act as downstream targets of PI3K-AKT and MAPK pathways.

\section{Correlation between 65 interacting proteins and tumor infiltrating immune cells}

Tumor progression is frequently accompanied by immune dysfunction. To investigate whether PI3K-AKT and MAPK pathways and their interacting proteins are associated with immune dysfunction in GC, we analyzed the correlation between genes corresponding to 65 interacting proteins and the infiltration levels of 6 immune cells including B cell, CD4+T cell, CD8+T cell, macrophage, neutrophil and dendritic cell based on TIMER database (Fig. 8B and supplementary table 2). For each type of immune cell, we selected 6 genes characteristic for the strongest correlation (positive or negative correlation) and statistical difference, and provided the relationship between their expression levels and infiltration level of immune cell in GC (Fig. 8C). Fig. 8B and 8C showed that the expression levels of genes were positively associated with infiltration levels of immune cells, excluding CDK4, CCNA2 and TWIST1 in B cell, pointing to a synergy between these genes and immune cells in GC. Inhibition of those interacting proteins by atomatine could thus affect the process and consequences of immune infiltration.

In order to investigate the underlying prognosis of immune cells, the Cox regression model was used to analyze 6 immune cells. Result showed that higher infiltration level of macrophage was a risk factor for GC, whereas no statistical differences were found in the other immune cells. We performed the KaplanMeier analysis of macrophage, suggesting that higher infiltration level of macrophage was correlated with poorer survival outcomes in GC (Fig. 8D and supplementary table 3). As a result of 8B and 8C, 6 genes strongly associated with macrophages were AKT3, VIM, FN1, MAPK10, SNAI2 and PIK3CG. Reference indices for further Kaplan-Meier analysis were determined by expression levels of these genes and infiltration level of macrophage simultaneously. Due to their positive correlations, two curves with the same predisposition of expression level and infiltration level (high gene expression + high macrophage and low gene expression + low macrophage) were more comparable. Curves demonstrated that the group of high levels often predicted poor prognosis (Fig. 8D). To evaluate the outcome significance of these genes to analysis whether high expression levels of genes predicted poor prognosis, similar to high infiltration level of macrophage. The Cox regression model is used to prove that higher expression levels of genes were risk factors for GC, including AKT3, VIM, FN1, MAPK10 and SNAI2, whereas no statistical differences were found in PIK3CG. Kaplan-Meier analysis indicated that higher expression levels of genes were correlated with poor survival outcomes in GC, including AKT3, VIM, FN1 and SNAI2, whereas no 
statistical differences were found in PIK3CG and MAPK10 (Fig. 8D and supplementary table 3). Considering that macrophages mediated gene expression in tumor cells by secreting interleukin- 6 and other cytokines, a-tomatine could improve prognosis of GC patients by inhibiting AKT3, VIM, FN1 and SNAI2, and at least partially counteract immune dysfunction triggered by macrophage infiltration.

\section{Discussion}

$\mathrm{GC}$ is one of the most common malignancies. Its tendency to recurrence and metastasis after surgery predicts a generally poor prognosis. To provide a potential treatment for $G C$, we investigated the mechanism of a-tomatine on human MGC803, BGC823, SGC7901 and SGC7901/DDP cells in vitro proliferation, apoptosis and migration. Result showed that a-tomatine decreased the levels of phosphorylation of AKT, phosphorylated MEK1/2 and phosphorylated ERK1/2 in a dose-dependent manner, suggesting that PI3K-AKT and MAPKs signaling pathways might be the crucial for a-tomatine to exert effects of anti-proliferation and anti-metastasis. During the development and metastasis of cancer, the vast majority of tumor cells move and are predisposed to attack organs and tissues where they occur, resulting in metastasis $[35,36]$. Combining with our conclusions, the migration capacity of GC cells is controlled at least in part by the PI3K-AKT and MAPKs signaling pathways. In addition, a-tomatine dosedependently inhibited the expression of TWIST, Slug and PARP in SGC7901/DDP. It was shown that atomatine partially inhibit the EMT pathway of GC resistant cells, leading to resist metastasis.

The inhibitory effects of PI3K-AKT and MAPKs pathways widely investigated should not only be summarized as proliferation and metastasis. PPI networks indicated that they might induce tumorigenesis, metastasis, and metabolism through other interacting proteins with high combined score. These proteins may be directly activated or inhibited by pathways or activate or inhibit pathways, or indirectly regulated by other signal transduction pathways. Systematic and comprehensive construction of a clear mechanism relationship is conducive to improve and enrich the treatment of GC. Immune dysfunction acts as a "promoter" in the development of tumors. When tumor cells secrete a variety of abnormal chemokines to recruit immune cells, they reduce or even eliminate antigens so that the immune response fails to respond effectively. An accumulation of immune cells results in infiltration. Previous studies have shown that IL-17 induces AKT-dependent activation of IL-6-JAK2-STAT3 in hepatocellular carcinoma [37], indicating that immune cells regulate the expression levels of genes in tumor cells by secreting such IL-6 or other cytokines. Our results showing the correlation between the expression levels of genes and the infiltration levels of immune cells also provide an explanation for this possibility. Further prognostic analysis demonstrated that the relationship between the infiltration level of macrophage and prognosis and the relationship between the expression levels of AKT3, VIM, FN1, SNAI2 and prognosis was frequently consistent. Therefore, a linear regulatory relationship may be existed between macrophages and these genes. a-Tomatine could at least partially antagonize the biological changes of tumor cells induced by the infiltration of macrophages, resulting in improving prognosis. Furthermore, the inhibitory effects of a-tomatine on gene might be regulatory factors on highly correlated infiltration levels of immune cells. 


\section{Conclusions}

In summary, we proposed a schematic explanation of potential mechanisms for the repressive effect of a-tomatine on GC cells (Fig. 9). Above results support that the anti-proliferative and anti-metastatic effects of a-tomatine on GC cells might be accomplished via inactivating PI3K-AKT and MAPKs pathways. In addition, the anti-proliferative and anti-metastatic effects of a-tomatine on cisplatin resistant GC cells provide an underlying manner to clinically reverse drug resistance. The effects of proteins related to PI3K-AKT and MAPKs pathways and the correlation between these proteins, immune infiltration and prognosis also suggest that the inhibitory effects of a-tomatine are not restricted to proliferation and metastasis. The regulatory mechanism of a-tomatine with metabolic process and immune function in $\mathrm{GC}$ needs to be further explored. $\mathrm{a}$-Tomatine have started shedding light on promising therapeutic strategies for GC with high metastasis and drug resistance, and could be further experimented through in vivo model to definitize if it is effective for confronting the proliferation, metastasis, drug resistance and immune infiltration of GC.

\section{List Of Abbreviations}

GC (gastric cancer); NSCLC (non-small cell lung cancer); MDR (multidrug resistance); ECM (extracellular matrix); PI3K (phosphatidylinositol 3-kinase); MAPK (mitogen-activated protein kinase); ERK1/2 (extracellular signal-regulated kinases 1 and 2); JNK (c-Jun N-terminal kinase); SAPK (stress-activated protein kinase ); VIM (Vimentin); PARP(poly ADP-ribose polymerase); FN1 (fibronectin 1);

\section{Declarations}

\section{Ethics approval and consent to participate}

Not applicable.

\section{Consent for publication}

Not applicable.

\section{Availability of data and materials}

The data used to support the findings of this study are included within the article and the supplementary information files.

\section{Competing interests}

No conflict of interest exits in the submission of this manuscript, and manuscript is approved by all authors for publication.

\section{Funding}


This work was supported by China Postdoctoral Science Foundation (No. 2019M653812XB). The National Science Foundation (81973533). Guangxi University High-level Innovation Team and the Project of Outstanding Scholars Program (2019AC03004) and Guangxi Science and Technology Project (AD19245197). The study funders contributed to the purchase of experimental items and had no role in the design, data acquisition, analyses, or data interpretation of this project.

\section{Authors' contributions}

ZD: conception, design and performance of the experiment, and wrote the manuscript. MSS and $\mathrm{YH}$ : analysis of data and contributed to the conception of the study. YLH, TWZ and MXW: contributed significantly to analysis and manuscript preparation. All authors have read and approved the manuscript.

\section{Acknowledgments}

We would like to thank all the people who participated in the design, writing and revision of this manuscript, as well as the project for funding this manuscript. This work was supported by China Postdoctoral Science Foundation (No. 2019M653812XB). The National Science Foundation (81973533). Guangxi University High-level Innovation Team and the Project of Outstanding Scholars Program (2019AC03004) and Guangxi Science and Technology Project (AD19245197).

\section{References}

1. Yan LH, Wei WY, Xie YB, Xiao Q. New insights into the functions and localization of the homeotic gene CDX2 in gastric cancer. World J Gastroenterol. 2014;20:3960-6. https://doi. org/10.3748/wjg.v20.i14.3960

2. Fidler IJ. The organ microenvironment and cancer metastasis. Differentiation. 2002;70:498-505. https://doi.org/10.1046/j.1432-0436.2002.700904.x

3. Shih YW, Chen PS, Wu CH, Jeng YF, Wang CJ. a-Chaconine-reduced Metastasis Involves a PI3K/Akt Signaling Pathway with Downregulation of NF-KB in Human Lung Adenocarcinoma A549 cells. J Agr Food Chem. 2008;55:11035-43. https://doi.org/10.1021/jf072423r

4. Khwaja A. Akt is more than just a Bad kinase. Nature. 1999;401:33-4. https://doi.org/ 10.1038/43354

5. Chan-Hui PY, Weaver R. Human mitogen-activated protein kinase kinase kinase mediates the stressinduced activation of mitogen-activated protein kinase cascades. Biochem J. 1998;336 ( Pt 3):599609. https://doi.org/10.1042/bj3360599

6. Trusolino L, Comoglio PM. Scatter-factor and semaphorin receptors: cell signalling for invasive growth. Nat Rev Cancer. 2002;2:289-300. https://doi.org/10.1038/nrc779

7. Zhang D, Zhou J, Gao J, Wu RY, Huang YL, Jin QW, et al. Targeting snoRNAs as an emerging method of therapeutic development for cancer. Am J Cancer Res. 2019;9:1504-16.

8. Chen PN, Hsieh YS, Chiou HL, Chu SC. Silibinin inhibits cell invasion through inactivation of both PI3K-Akt and MAPK signaling pathways. Chem Biol Interact. 2005;156:141-50. 
https://doi.org/10.1016/j.cbi.2005.08.005

9. Kwon GT, Cho HJ, Chung WY, Park KK, Moon A, Park JH. Isoliquiritigenin inhibits migration and invasion of prostate cancer cells: possible mediation by decreased JNK/AP-1 signaling. J Nutr Biochem. 2009;20:663-76. https://doi.org/10.1016/j.jnutbio.2008.06.005

10. Lee SJ, Park SS, Lee US, Kim WJ, Moon SK. Signaling pathway for TNF-alpha-induced MMP-9 expression: mediation through p38 MAP kinase, and inhibition by anti-cancer molecule magnolol in human urinary bladder cancer 5637 cells. Int Immunopharmacol. 2008;8:1821-6. https://doi.org/10.1016/j.intimp.2008.08.018

11. Shieh JM, Cheng TH, Shi MD, Wu PF, Chen Y, Ko SC, et al. a-Tomatine Suppresses Invasion and Migration of Human Non-Small Cell Lung Cancer NCl-H460 Cells Through Inactivating FAK/PI3K/Akt Signaling Pathway and Reducing Binding Activity of NF-KB. Cell Biochem Biophys. 2011;60:297-310. https://doi.org/10.1007/s12013-011-9152-1

12. Zhou Z, Wang C, Liu H, Huang Q, Wang M, Lei Y. Cadmium induced cell apoptosis, DNA damage, decreased DNA repair capacity, and genomic instability during malignant transformation of human bronchial epithelial cells. Int J Med Sci. 2013;10:1485-96. https://doi.org/10.7150/ijms.6308

13. Krakauer T, Li BQ, Young HA. The flavonoid baicalin inhibits superantigen-induced inflammatory cytokines and chemokines. FEBS Lett. 2001;500:52-5. https://doi.org/10.1016/ s00145793(01)02584-4

14. Shih YW, Shieh JM, Wu PF, Lee YC, Chen YZ, Chiang TA. Alpha-tomatine inactivates PI3K/Akt and ERK signaling pathways in human lung adenocarcinoma A549 cells: effect on metastasis. Food Chem Toxicol. 2009;47:1985-95. https://doi.org/10.1016/j.fct.2009.05.011

15. Friedman M, Levin CE. a-Tomatine content in tomato and tomato products determined by HPLC with pulsed amperometric detection. J Agr Food Chem. 1995;43:1507-11. https://doi.org/10.1021/jf00054a017

16. Lee KR, Kozukue N, Han JS, Park JH, Chang EY, Baek EJ, et al. Glycoalkaloids and metabolites inhibit the growth of human colon (HT29) and liver (HepG2) cancer cells. J Agric Food Chem. 2004;52:28329. https://doi.org/10.1021/jf030526d

17. Rudolf K, Rudolf E. Antiproliferative effects of a-tomatine are associated with different cell death modalities in human colon cancer cells. J Funct Foods. 2016;27:491-502. https://doi.org/10.1016/j.jff.2016.10.005

18. Morrow WJ, Yang YW, Sheikh NA. Immunobiology of the Tomatine adjuvant. Vaccine. 2004;22:23804. https://doi.org/10.1016/j.vaccine.2004.03.022

19. Chiu FL, Lin JK. Tomatidine inhibits iNOS and COX-2 through suppression of NF-kappaB and JNK pathways in LPS-stimulated mouse macrophages. FEBS Lett. 2008;582:2407-12. https://doi.org/10.1016/j.febslet.2008.05.049

20. Lee ST, Wong PF, He H, Hooper JD, Mustafa MR. Alpha-tomatine attenuation of in vivo growth of subcutaneous and orthotopic xenograft tumors of human prostate carcinoma PC-3 cells is 
accompanied by inactivation of nuclear factor-kappa B signaling. PLoS One. 2013;8:e57708. https://doi.org/10.1371/journal.pone.0057708

21. Szklarczyk D, Franceschini A, Kuhn M, Simonovic M, Roth A, Minguez P, et al. The STRING database in 2011: functional interaction networks of proteins, globally integrated and scored. Nucleic Acids Res. 2011;39:D561-8. https://doi.org/10.1093/nar/gkq973

22. Smoot ME, Ono K, Ruscheinski J, Wang PL, Ideker T. Cytoscape 2.8: new features for data integration and network visualization. Bioinformatics. 2011;27:431-2. https://doi.org/ $\underline{10.1093 / \text { bioinformatics/btq } 675}$

23. Chin $\mathrm{CH}$, Chen $\mathrm{SH}$, Wu HH, Ho CW, Ko MT, Lin CY. cytoHubba: identifying hub objects and subnetworks from complex interactome. BMC Syst Biol. 2014;8 Suppl 4:S11. https://doi.org/10.1186/1752-0509-8-S4-S11

24. Li T, Fan J, Wang B, Traugh N, Chen Q, Liu JS, et al. TIMER: A Web Server for Comprehensive Analysis of Tumor-Infiltrating Immune Cells. Cancer Res. 2017;77:e108-e10. https://doi.org/10.1158/00085472.CAN-17-0307

25. Evan Gl, Vousden KH. Proliferation, cell cycle and apoptosis in cancer. Nature. 2001;411:342-8. https://doi.org/10.1038/35077213

26. Yaacoub K, Pedeux R, Tarte K, Guillaudeux T. Role of the tumor microenvironment in regulating apoptosis and cancer progression. Cancer Lett. 2016;378:150-9. https:// doi.org/10.1016/j.canlet.2016.05.012

27. Minn AJ, Gupta GP, Siegel PM, Bos PD, Shu W, Giri DD, et al. Genes that mediate breast cancer metastasis to lung. Nature. 2005;436:518-24. https://doi.org/10.1038/nature03799

28. Wang $G$, Sun $M$, Jiang $Y$, Zhang $T$, Sun $W$, Wang $H$, et al. Anlotinib, a novel small molecular tyrosine kinase inhibitor, suppresses growth and metastasis via dual blockade of VEGFR2 and MET in osteosarcoma. Int J Cancer. 2019;145:979-93. https://doi.org/10.1002/ijc.32180

29. Pozharskaya V, Torres-Gonzalez E, Rojas M, Gal A, Amin M, Dollard S, et al. Twist: a regulator of epithelial-mesenchymal transition in lung fibrosis. PLoS One. 2009;4:e7559.

https://doi.org/10.1371/journal.pone.0007559

30. Vuoriluoto K, Haugen H, Kiviluoto S, Mpindi JP, Nevo J, Gjerdrum C, et al. Vimentin regulates EMT induction by Slug and oncogenic $\mathrm{H}$-Ras and migration by governing Axl expression in breast cancer. Oncogene. 2011;30:1436-48. https://doi.org/10.1038/onc.2010.509

31. Allison Stewart C, Tong P, Cardnell RJ, Sen T, Li L, Gay CM, et al. Dynamic variations in epithelial-tomesenchymal transition (EMT), ATM, and SLFN11 govern response to PARP inhibitors and cisplatin in small cell lung cancer. Oncotarget. 2017;8:28575-87. https://doi.org/10.18632/oncotarget.15338

32. Polioudaki H, Agelaki S, Chiotaki R, Politaki E, Mavroudis D, Matikas A, et al. Variable expression levels of keratin and vimentin reveal differential EMT status of circulating tumor cells and correlation with clinical characteristics and outcome of patients with metastatic breast cancer. BMC Cancer. 2015;15:399. https://doi.org/10.1186/s12885-015-1386-7 
33. Zhou M, Liu X, Li Z, Huang Q, Li F, Li CY. Caspase-3 regulates the migration, invasion and metastasis of colon cancer cells. Int J Cancer. 2018;143:921-30. https://doi.org/ 10.1002/ijc.31374

34. Rogers CD, Saxena ABronner ME. Sip1 mediates an E-cadherin-to-N-cadherin switch during cranial neural crest EMT. J Cell Biol. 2013;203:835-47. https://doi.org/10.1083/jcb. 201305050

35. Parsons JT. Focal adhesion kinase: the first ten years. J Cell Sci. 2003;116:1409-16. https://doi.org/10.1242/jcs.00373

36. Sonoda Y, Watanabe S, Matsumoto Y, Aizu-Yokota E, Kasahara T. FAK is the upstream signal protein of the phosphatidylinositol 3-kinase-Akt survival pathway in hydrogen peroxide-induced apoptosis of a human glioblastoma cell line. J Biol Chem. 1999;274:10566-70.

https://doi.org/10.1074/jbc.274.15.10566

37. Gu FM, Li QL, Gao Q, Jiang JH, Zhu K, Huang XY, et al. IL-17 induces AKT-dependent IL6/JAK2/STAT3 activation and tumor progression in hepatocellular carcinoma. Mol Cancer. 2011;10:150. https://doi.org/10.1186/1476-4598-10-150

\section{Figures}


A

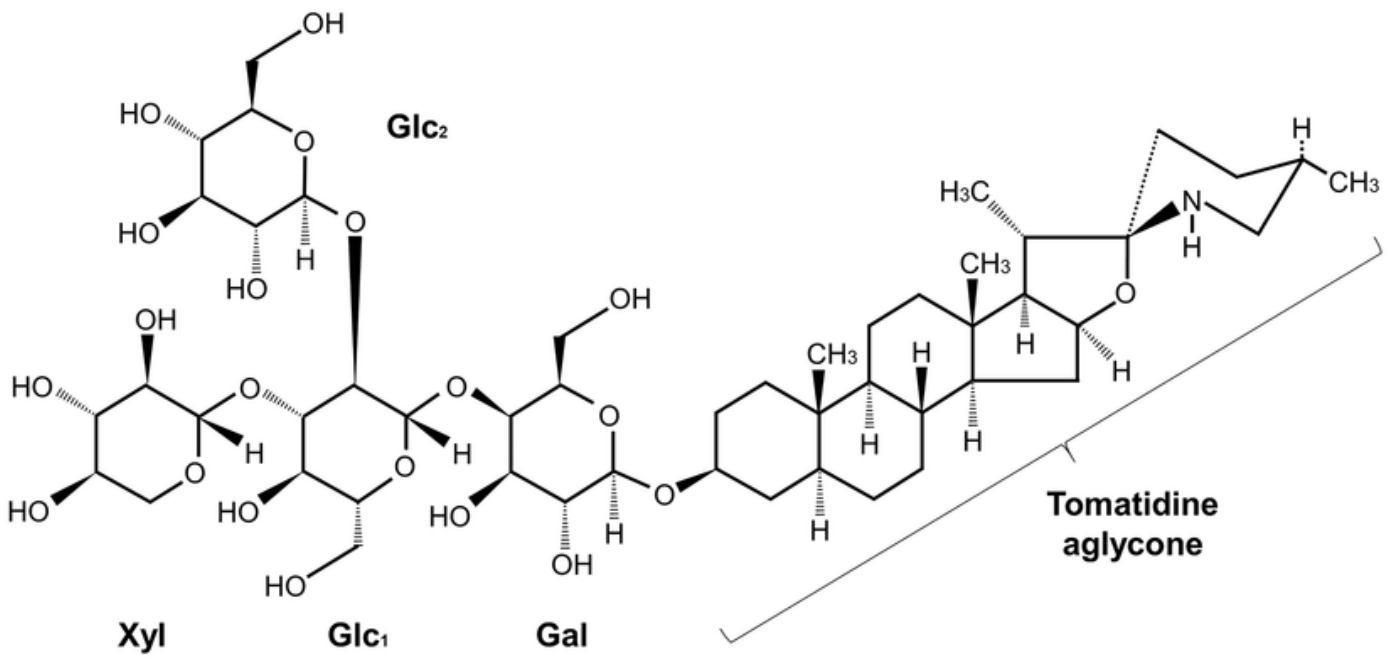

$\alpha$-Tomatine

B
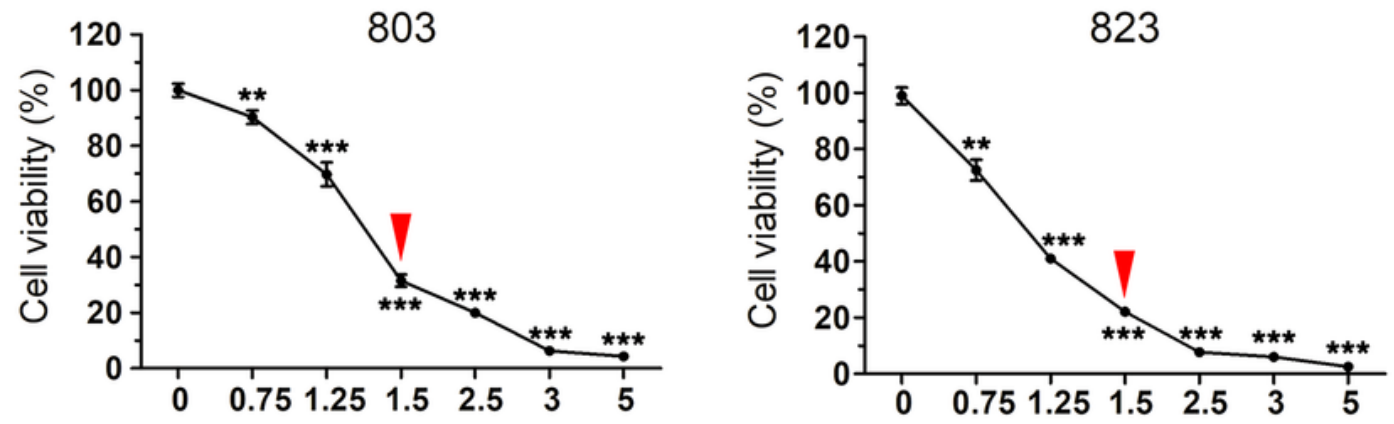

$\alpha$-Tomatine $(\mu \mathrm{M})$

$\alpha$-Tomatine $(\mu \mathrm{M})$
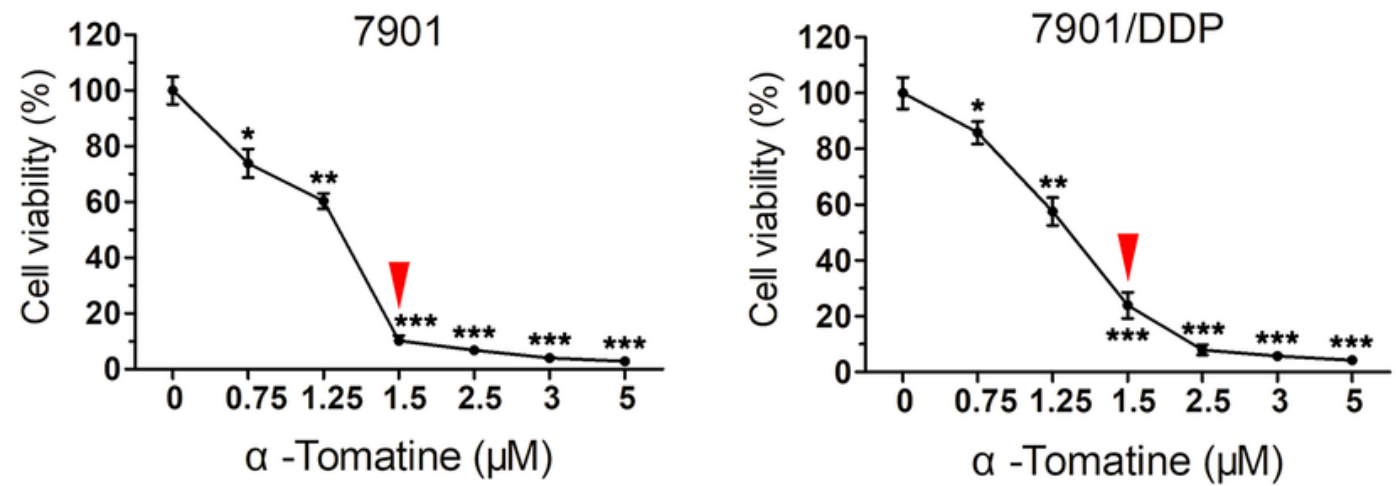

C

\begin{tabular}{|c|c|c|c|c|} 
Cell line & 803 & 823 & 7901 & $7901 / \mathrm{DDP} P$ \\
\hline $\mathrm{IC}_{50}(24 \mathrm{~h})(\boldsymbol{N} \mathrm{M} / \mathrm{I})$ & $1.412 \pm 0.108$ & $1.055 \pm 0.047$ & $1.147 \pm 0.142$ & $1.250 \pm 0.156$ \\
\hline
\end{tabular}

Figure 1

The effects of a-tomatine on the viability and growth in MGC803, BGC823, SGC7901 and SGC7901/DDP cells. (A) Chemical structure of a-Tomatine. (B) Cultured cells were treated with various concentration ( 0 , $0.75,1,1.5,2.5,3$ and $5 \mu \mathrm{M}$ ) of a-tomatine for $24 \mathrm{~h}$. Cell viability was determined by CCK8 kit. Cell survival was negatively correlated with increased concentration, which was measured spectrophotometrically at $450 \mathrm{~nm}$. Values were expressed as mean \pm SD of three independent 
experiments ( ${ }^{\star} \mathrm{P}<0.05 ;{ }^{* * \mathrm{P}<0.01 ; * \star \star} \mathrm{P}<0.001$ ) compared with the control group (dose 0 ). (C) We calculated the IC50 values of $4 \mathrm{GC}$ cells by GraphPad Prism 5. Values were expressed as mean \pm SD of three independent experiments.

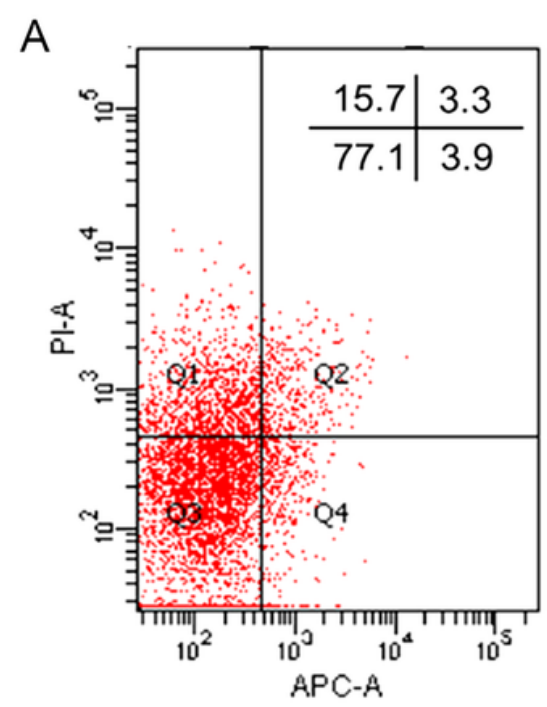

MGC803

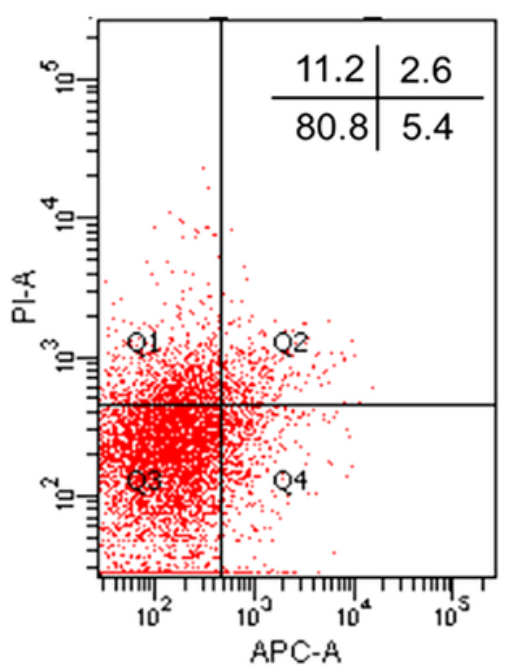

SGC7901

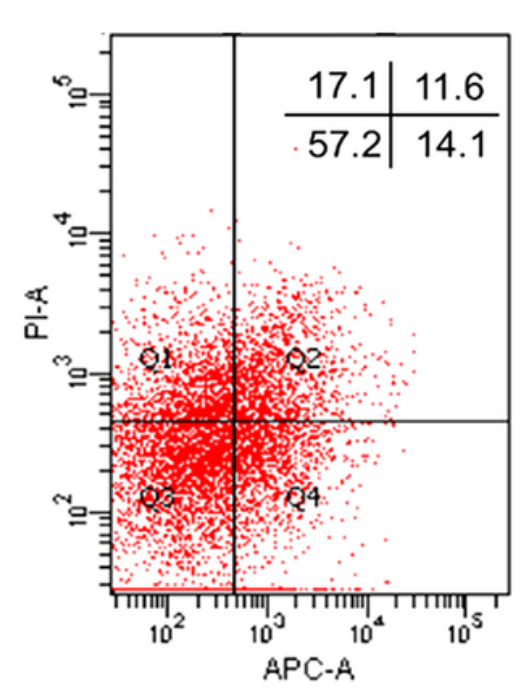

MGC803 + a-tomatine

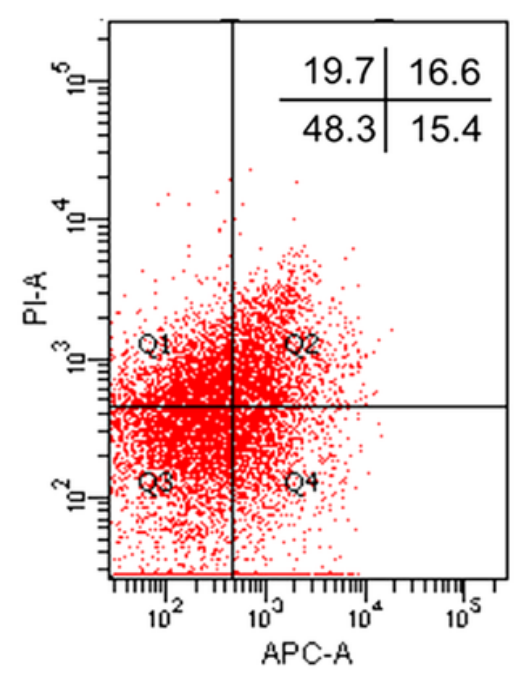

SGC7901 + $\alpha$-tomatine
B
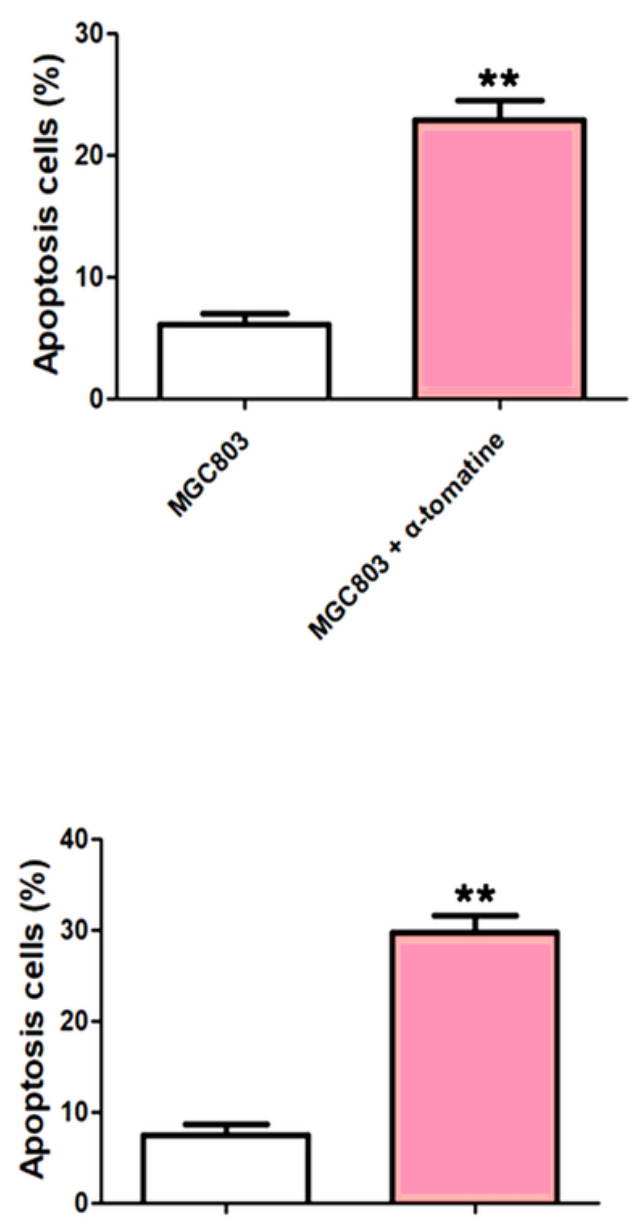

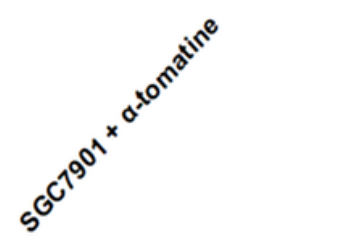

\section{Figure 2}

The apoptosis effects of a-tomatine on MGC803 and SGC7901 cells. (A) Flow cytometry results showed that the percentage of apoptosis in MGC803 and SGC7901 cells treated with $0 \mu \mathrm{M}$ and $1 \mu \mathrm{M}$ of $\mathrm{a}-$ tomatine. (B) Percentage of apoptotic cells treated with $0 \mu \mathrm{M}$ and $1 \mu \mathrm{M}$ of a-tomatine in MGC803 and SGC7901 cells. Values are expressed as mean \pm SD of three independent experiments $\left({ }^{\star} P<0.05 ; * \star P\right.$ $<0.01 ; * * * \mathrm{P}<0.001)$. 


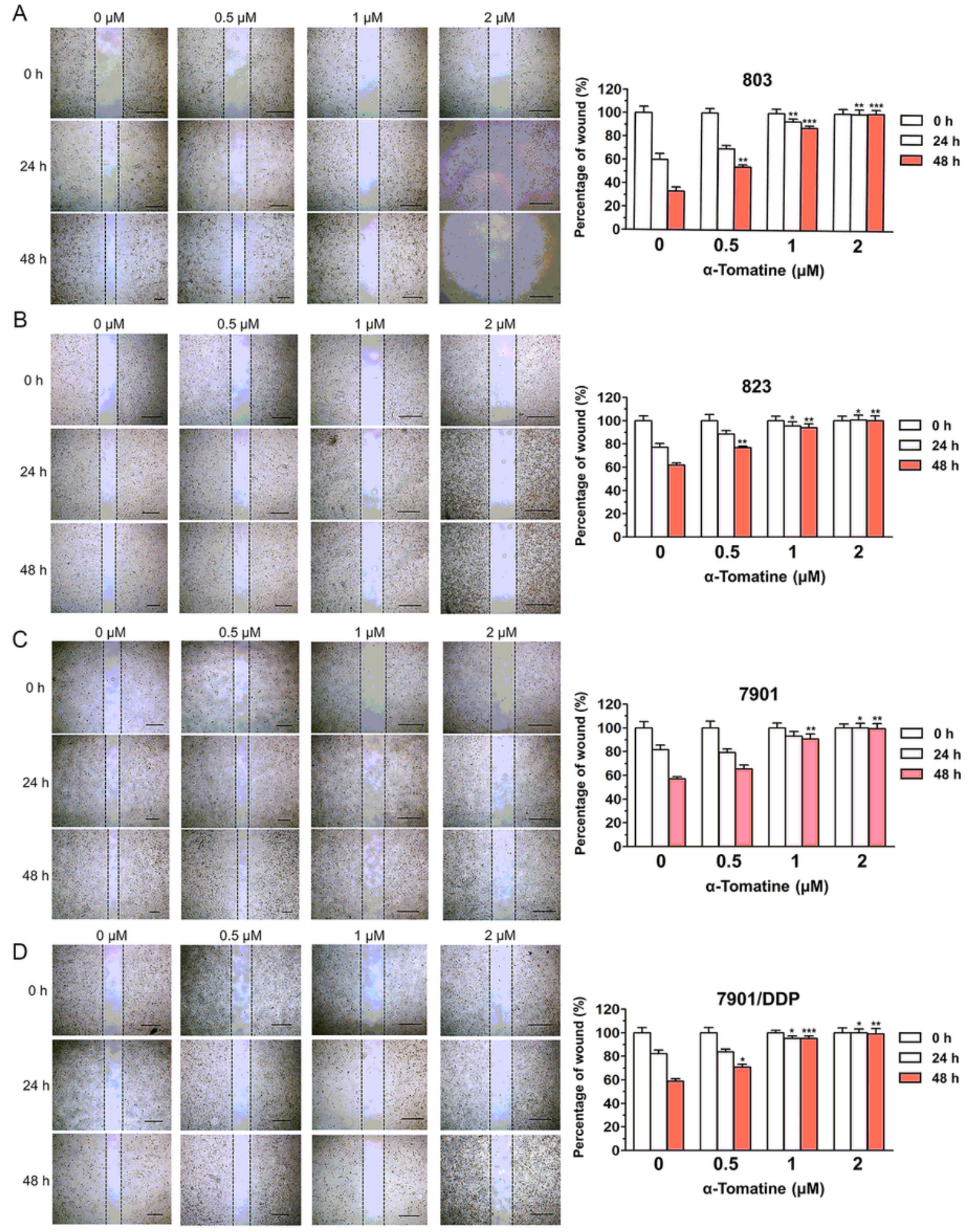

\section{Figure 3}

Effect of a-tomatine on the migration in MGC803, BGC823, SGC7901 and SGC7901/DDP cells. In woundhealing assay, monolayers of $4 \mathrm{GC}$ cells were scraped by a sterile micropipette tip and the cells were treated with various concentrations $(0,0.5,1$ and $2 \mu \mathrm{M})$ of a-tomatine for 0,24 , and $48 \mathrm{~h}$. The healing of the wound was photographed after indicated times $(0,24$ and $48 \mathrm{~h})$ by microscopy. Dotted black lines manifest the wound edge. The ruler lines in the bottom right corners manifest the distance between the 
dotted lines. The percentages of wound areas were marked at various concentrations of a-tomatine and intervention times by ImageJ, and were calculated by GraphPad Prism 5. Values were presented as mean \pm SD of three independent experiments ( $\left.{ }^{*}<0.05 ; * \star P<0.01 ; * \star * P<0.001\right)$. (A) Images and percentages of the healing of the wound of MGC803 cell. (B) Images and percentages of the healing of the wound of BGC823 cell. (C) Images and percentages of the healing of the wound of SGC7901 cell. (D) Images and percentages of the healing of the wound of SGC7901/DDP cell.
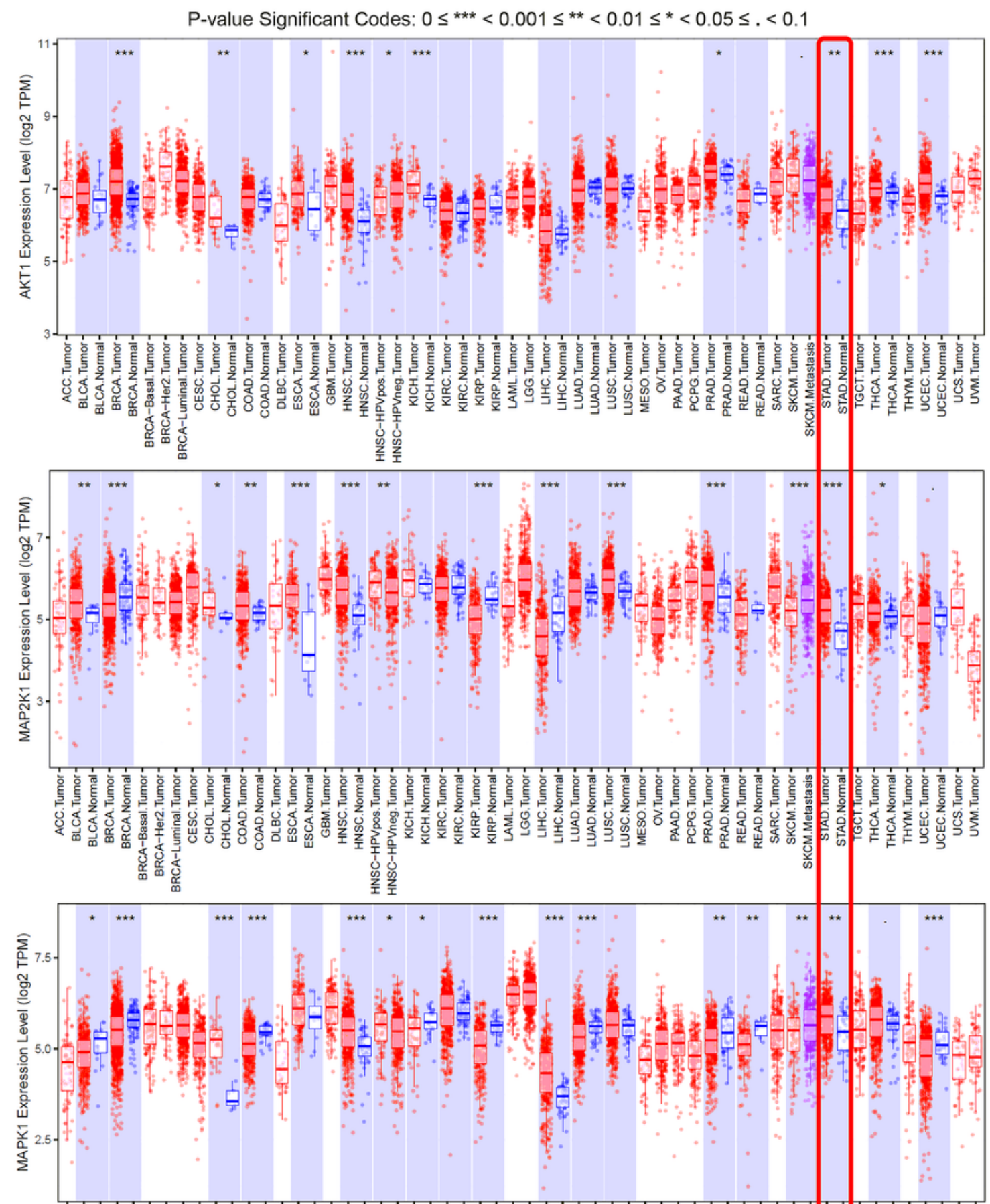

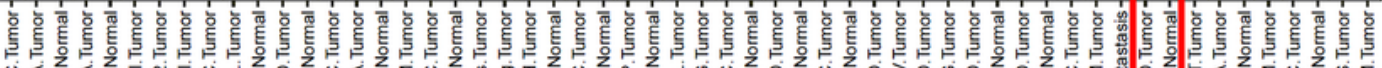

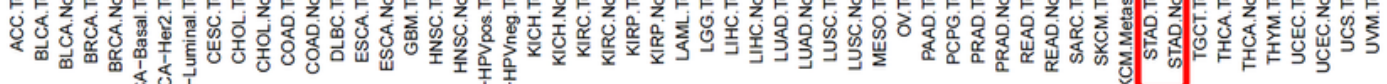

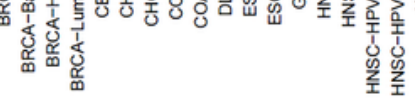


The differential expression between the cancerous tissues and adjacent normal tissues for AKT1, MAP2K1 and MAPK1 (*P <0.05; **P $<0.01 ; * * * P<0.001)$.

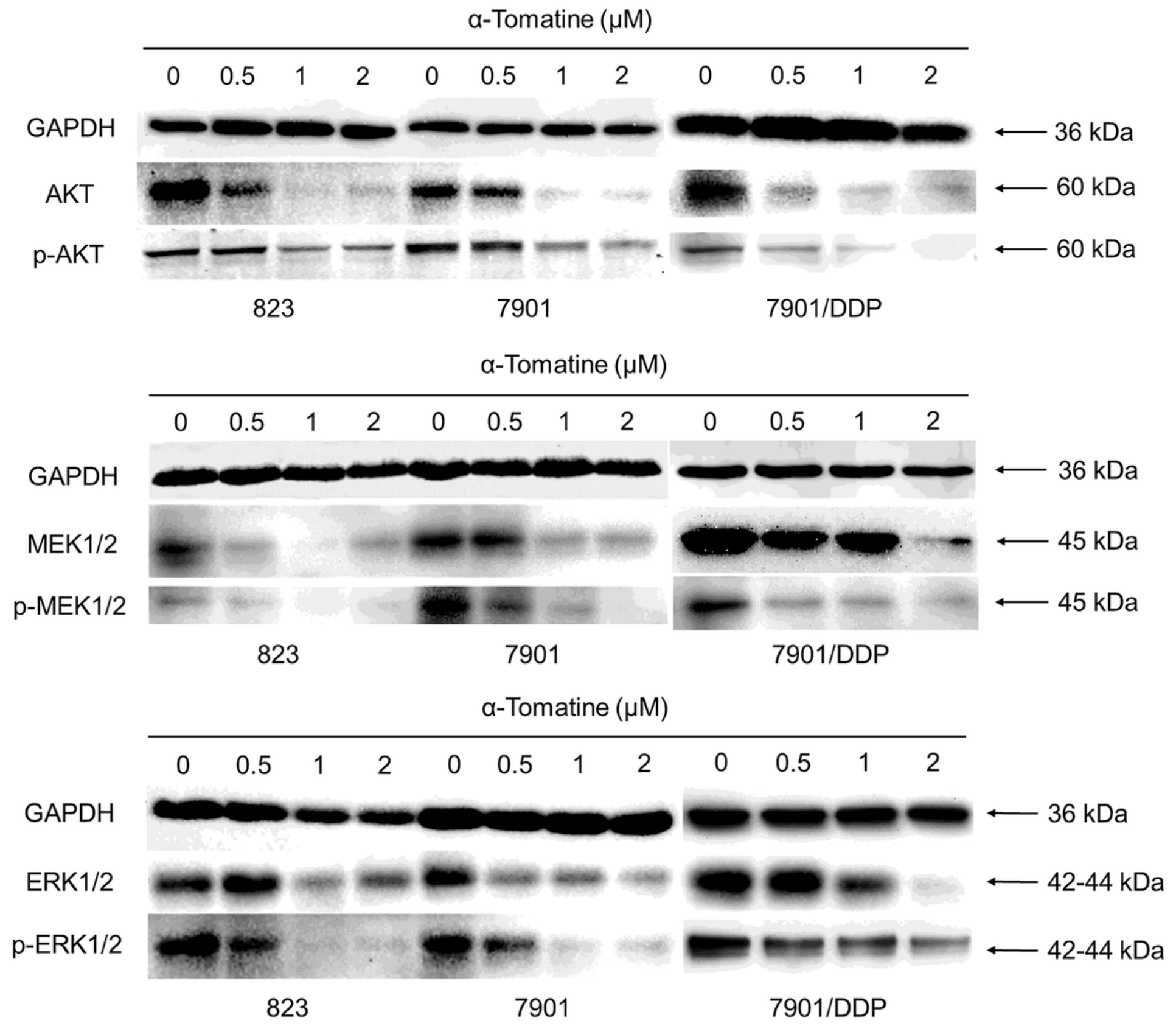

\section{Figure 5}

The effects of a-tomatine on PI3K-AKT and MAPK signaling in BGC823, SGC7901 and SGC7901/DDP cells. Cells were treated with various concentrations $(0,0.5,1$ and $2 \mu \mathrm{M})$ of a-tomatine for $24 \mathrm{~h}$, after which cells were harvested and analyzed for the expressions of AKT, phospho-AKT, MEK1/2, phosphoMEK1/2, MAPK (ERK1/2 and phospho-ERK1/2). The protein levels were determined by Western blot. GAPDH was used as an internal control. 

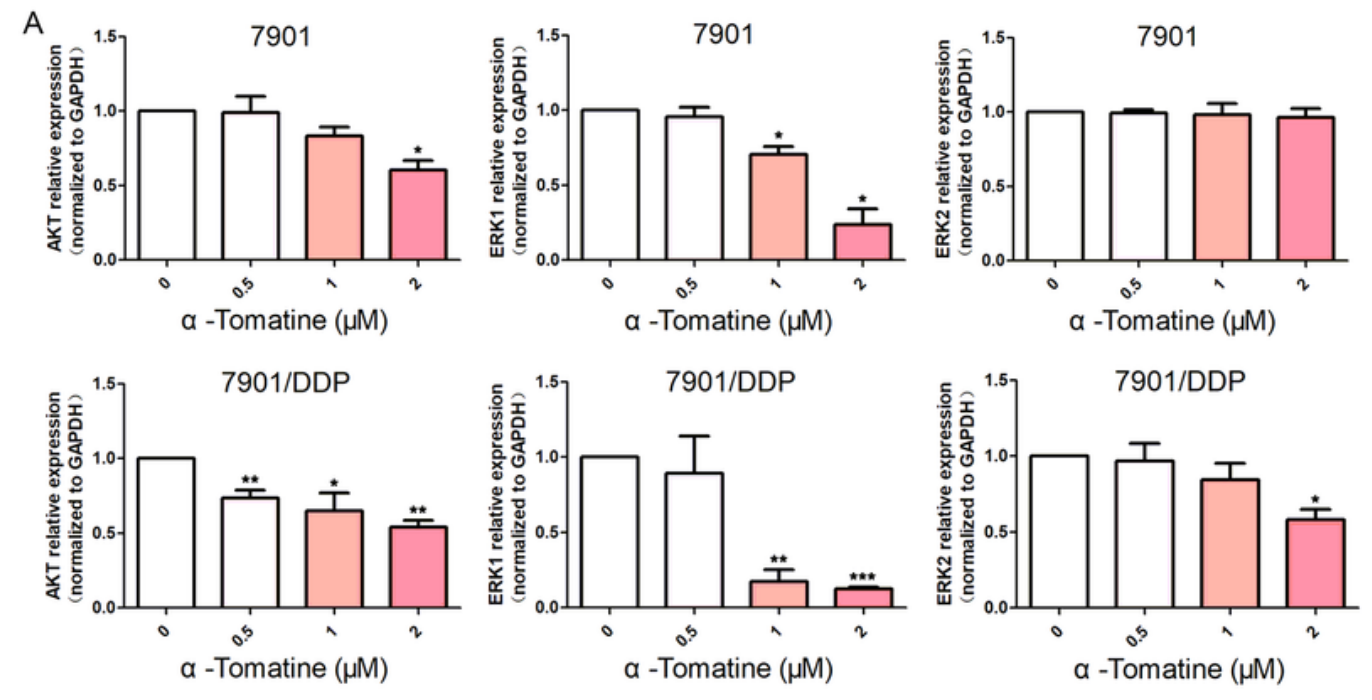

B
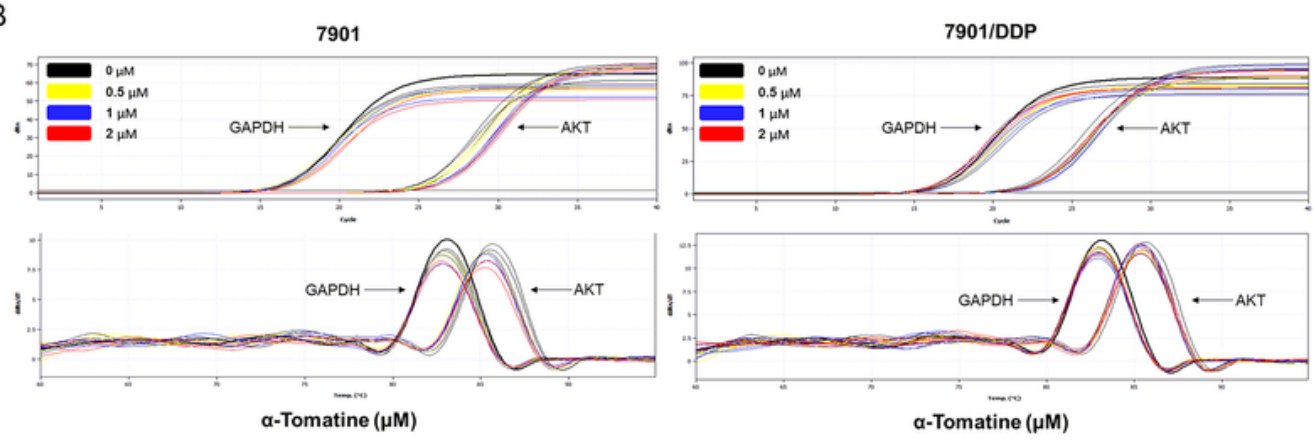

7901
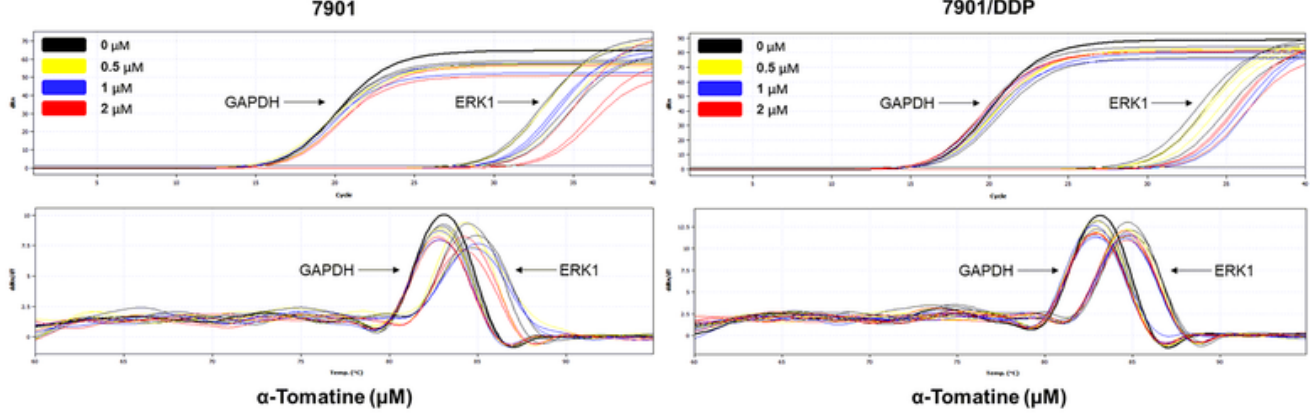

7901
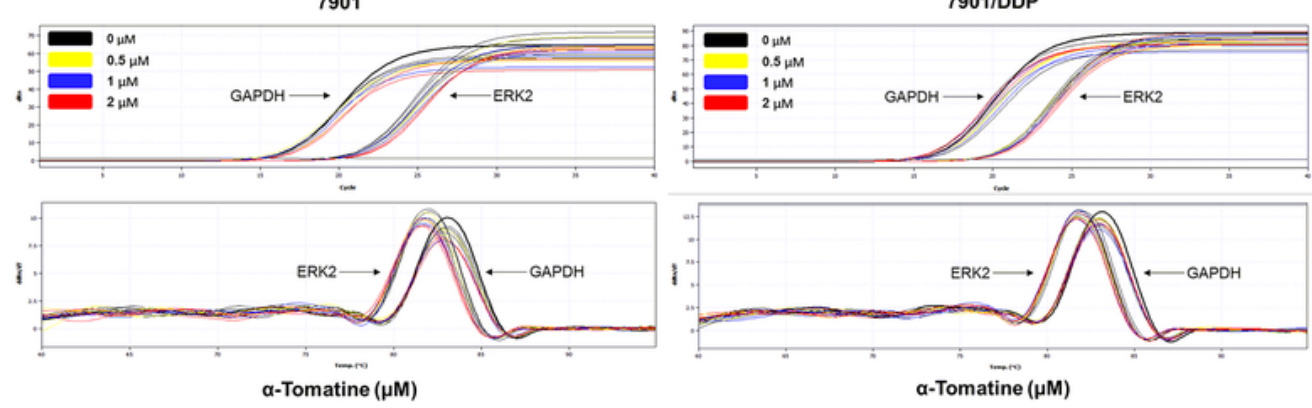

Figure 6

(A) Real-time quantitative RT-PCR of AKT, ERK1 and ERK2 expressions in cells treated with indicated doses of a-tomatine and harvested at $24 \mathrm{~h}$. GADPH were used as internal controls. Values were presented as mean $\pm \mathrm{SD}$ of three independent experiments ( ${ }^{\star} \mathrm{P}<0.05 ;{ }^{* \star} \mathrm{P}<0.01 ;{ }^{* \star *} \mathrm{P}<0.001$ ). (B) Amplification curves and primer dissolution curves of AKT, ERK1 and ERK2 were obtained in SGC7901 and SGC7901/DDP cells treated with different concentrations of a-tomatine $(0,0.5,1$ and $2 \mu \mathrm{M})$. 

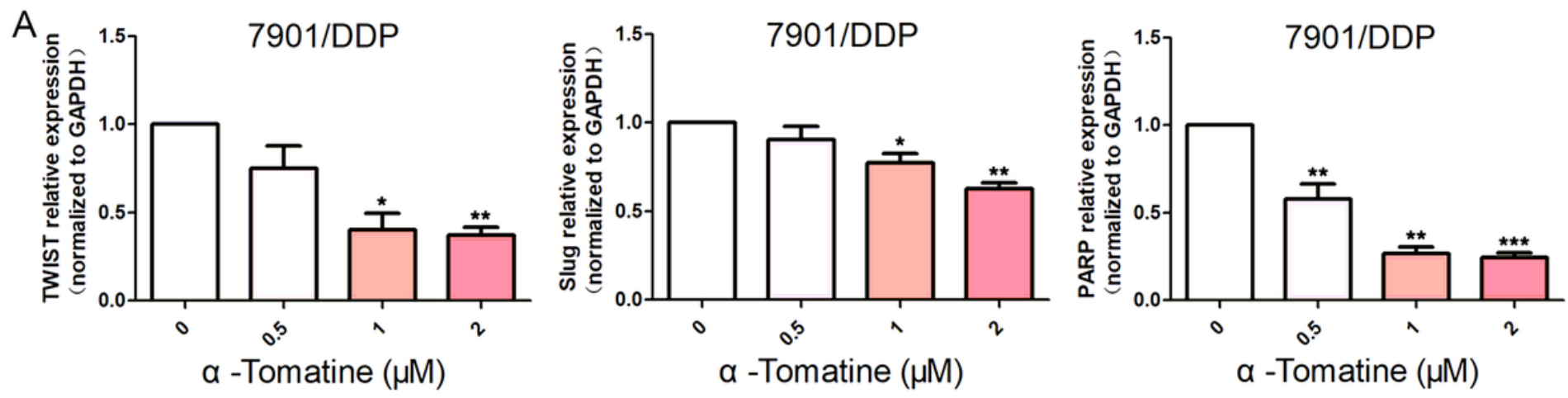

B

7901/DDP
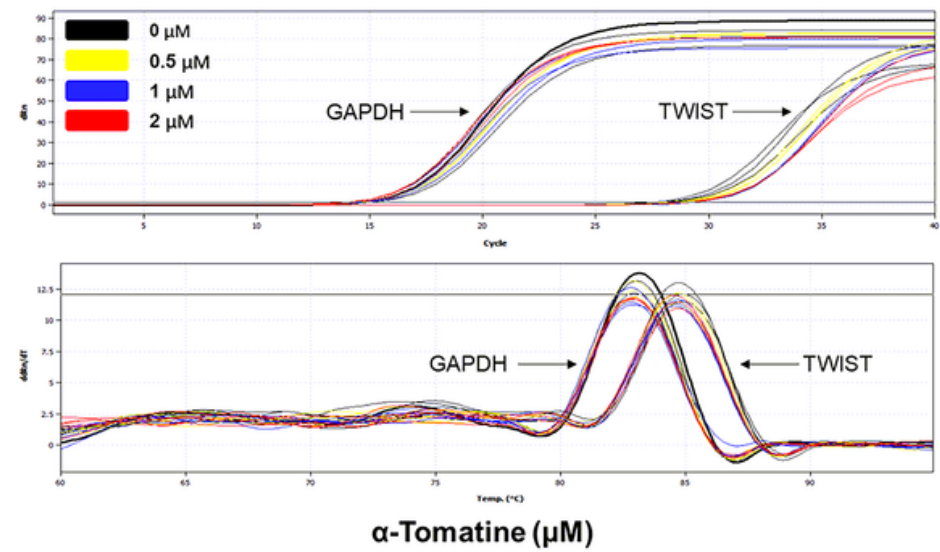

7901/DDP
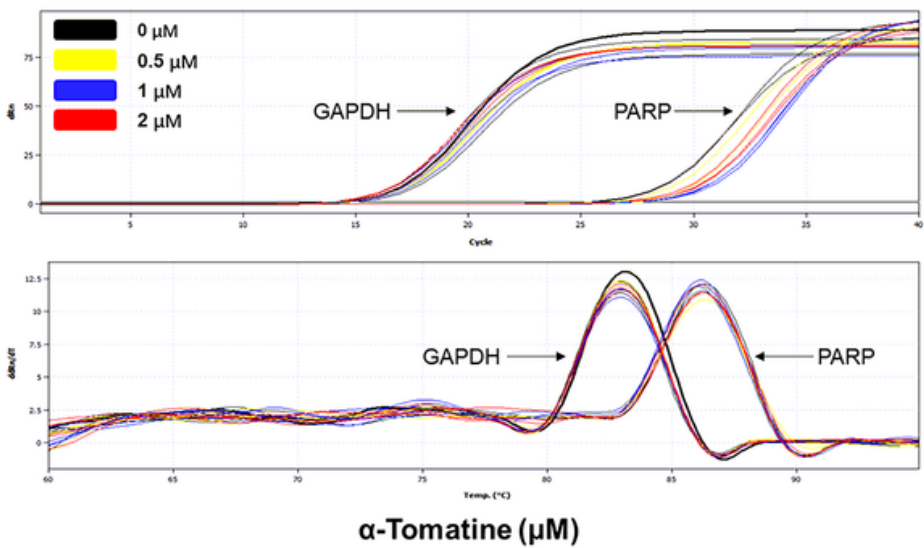

7901/DDP
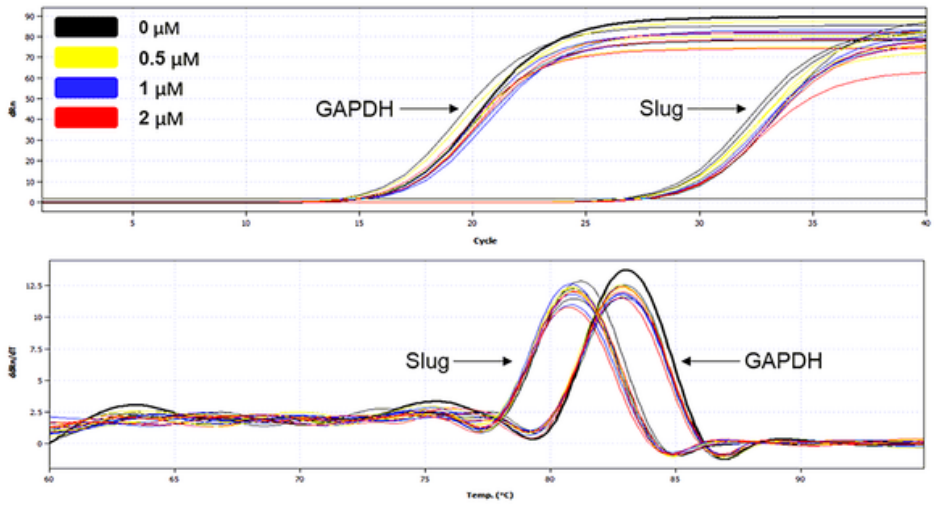

$\alpha$-Tomatine $(\mu \mathrm{M})$

Figure 7

(A) Real-time quantitative RT-PCR of TWIST, Slug and PARP expressions in SGC7901/DDP cell treated with indicated doses of a-tomatine and harvested at $24 \mathrm{~h}$. GADPH were used as internal controls. Values were presented as mean \pm SD of three independent experiments ( $\left.{ }^{*}<<0.05 ; \star \star P<0.01 ; * \star * P<0.001\right)$. (B) Amplification curves and primer dissolution curves of TWIST, Slug and PARP were obtained in SGC7901/DDP cells treated with different concentrations of a-tomatine $(0,0.5,1$ and $2 \mu \mathrm{M})$. 
A

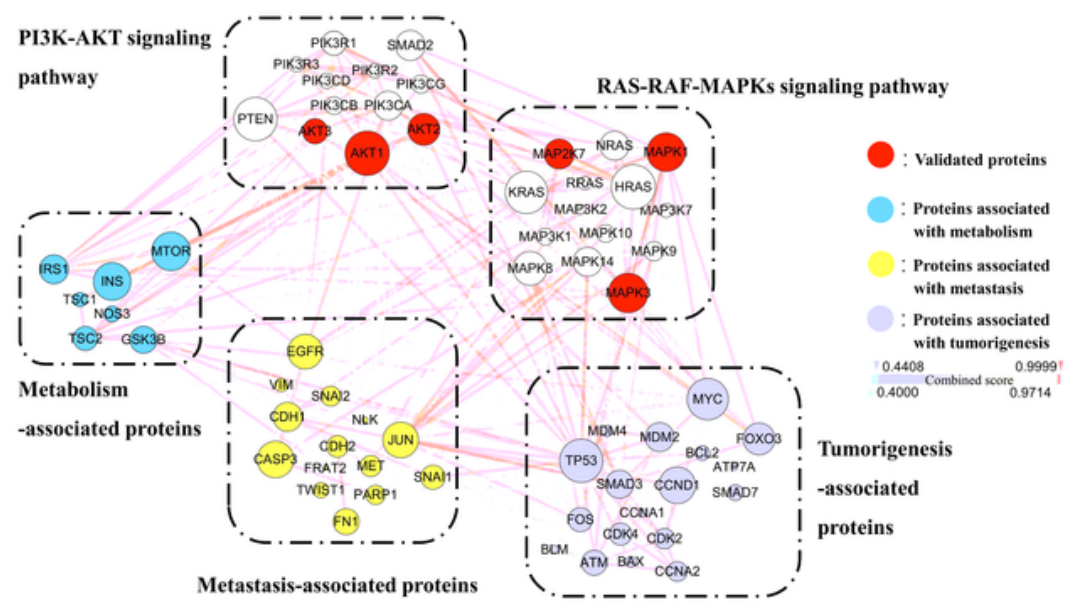

B
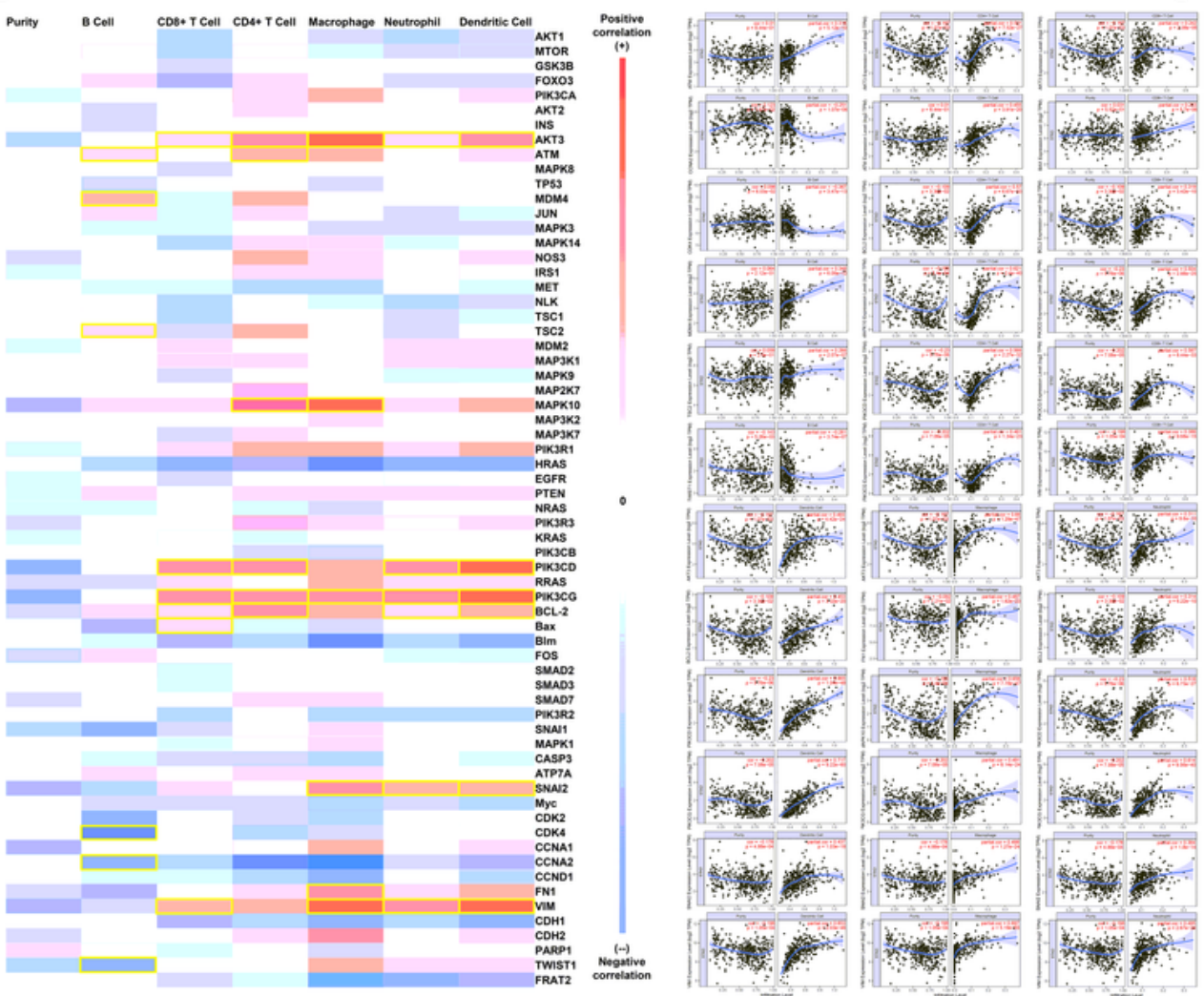

D

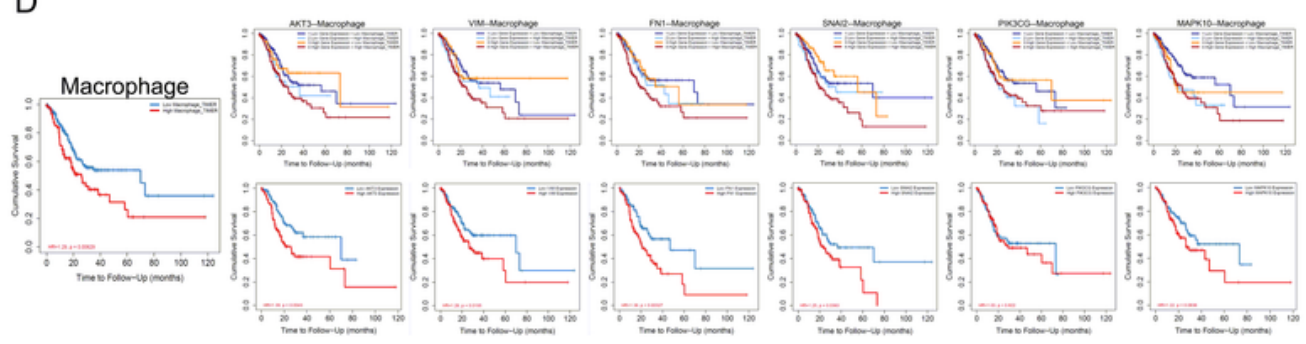

\section{Figure 8}

(A) Proteins of different subtypes in PI3K-AKT and MAPKs pathways and proteins related to tumorigenesis, metastasis, metabolism were used to construct the PPI network. (B) Heatmap of the correlation between the infiltration levels of 6 immune cells and 65 genes corresponding to interacting proteins. (C) The correlation between the infiltration levels of 6 immune cells and 6 genes most strongly 
associated with them. (D) Survival analysis of macrophage, AKT3, VIM, FN1, SNAI2, PIK3CG and MAPK10.

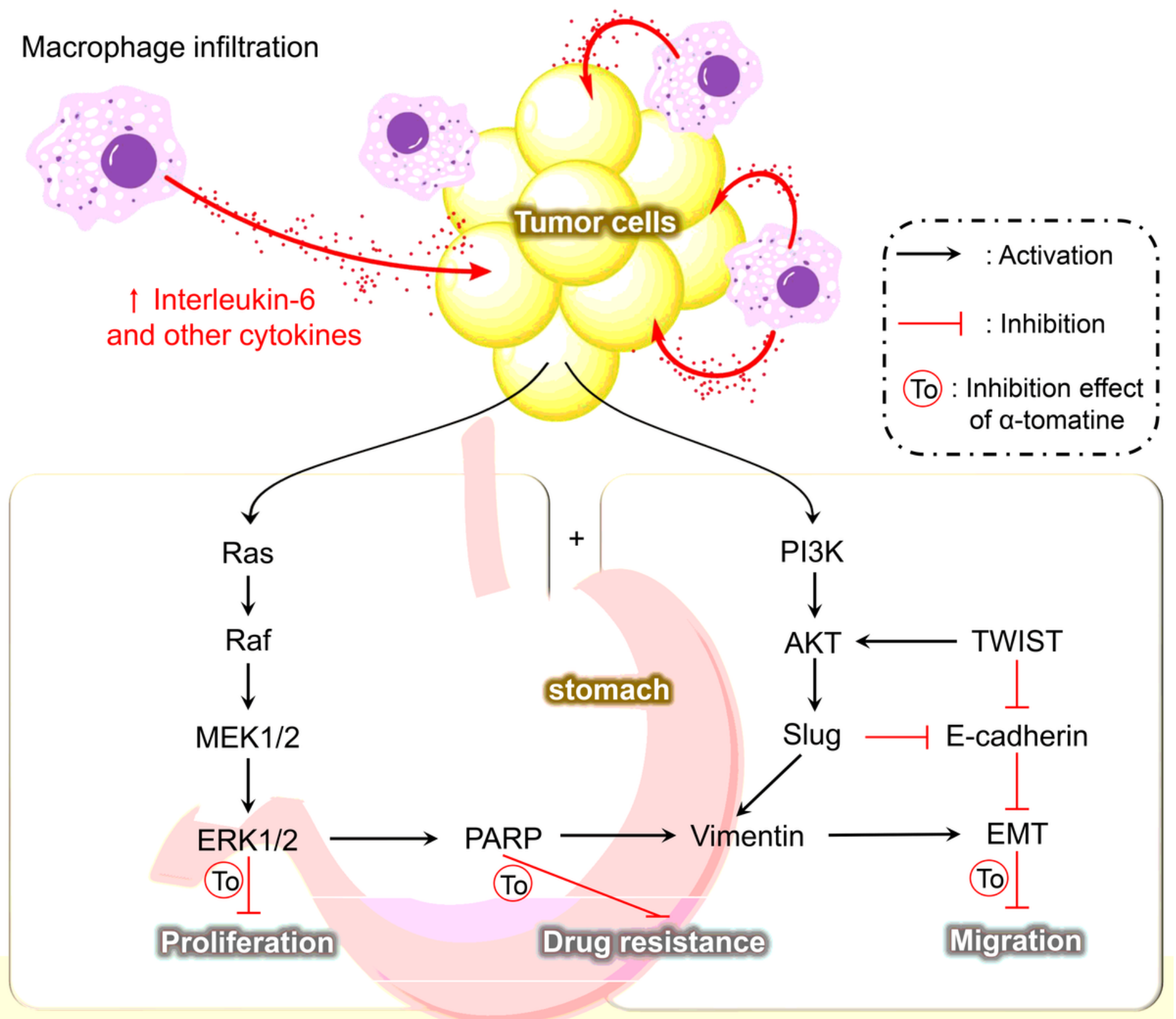

Figure 9

We used ChemDraw software to draw the mechanisms by which a-tomatine suppresses proliferation, metastasis and drug resistance of GC cells. a-Tomatine represses proliferation and metastasis of GC cells via inhibiting the PI3K-AKT and MAPKs pathways, and represses TWIST, Slug and PARP expressions so as to reverse drug resistance.

\section{Supplementary Files}


This is a list of supplementary files associated with this preprint. Click to download.

- supplementaryfigure1 originalimage.tif

- supplementarytable3.docx

- supplementarytable2.xlsx

- supplementarytable1.xlsx 